Disponível em

http://www.anpad.org.br/rac

RAC, Rio de Janeiro, v. 19, n. 6, art. 5, pp. 750-771, Nov./Dez. 2015

http://dx.doi.org/10.1590/1982-7849rac2015150001

\title{
Análise da Competitividade da Cadeia Produtiva do Leite em Pó Integral
}

\author{
Analysis of Competitiveness of the Whole Milk Powder Production Chain
}

João Batista de Freitas

Universidade do Estado do Rio Grande do Norte - UERN

Jean Philippe Palma Revillion

Universidade Federal do Rio Grande do Sul - UFRGS

Luiz Clovis Belarmino Empresa Brasileira de Pesquisa Agropecuária - EMBRAPA

Artigo recebido em 25.07.2014. Última versão recebida em 23.04.2015. Aprovado em 29.04.2015. 


\title{
Resumo
}

O artigo teve como objetivo analisar a competitividade de três cadeias produtivas do leite em pó integral no Rio Grande do Sul (Brasil), com três diferentes níveis tecnológicos (baixo, médio e alto) no elo de produção de matériaprima. O método utilizado foi o instrumento Policy Analysis Matrix (PAM), desenvolvido por Monke e Pearson (1989). Os resultados evidenciaram que todas as cadeias produtivas estudadas apresentaram ganhos na forma de lucros privados (ou seja, há remuneração dos agentes acima dos custos de oportunidade e da depreciação dos investimentos) e ganhos nos lucros sociais (ou seja, há eficiência econômica e vantagens comparativas). Por fim, concluiu-se que a cadeia produtiva com o elo de produção de médio nível tecnológico, intensiva em uso de insumos de produção, apresentou mais efeitos penalizadores de políticas tributárias do que aquelas com menores índices de adoção de insumos modernos, conforme valores das Razões dos Custos Privados (RCPs), que foram 0,72, 0,46 e 0,26, respectivamente, para as cadeias produtivas com médio, baixo e alto nível tecnológico no elo de produção de matéria-prima.

Palavras-chave: Policy Analysis Matrix; agronegócio do leite; indicadores econômicos; níveis tecnológicos; políticas públicas.

\begin{abstract}
This paper aimed at analyzing competitiveness of three whole milk powder production chains in Rio Grande do Sul (Brazil) with three different technological levels (low, medium and high) of raw material production using Policy Analysis Matrix (PAM) methodology, developed by Monke and Pearson (1989). The results showed that all of the production chains studied generated earnings in the form of both private profits (i.e. the remuneration of the agents is higher than the opportunity costs and investment depreciation) and social profits (i.e. there are economic effectiveness and comparative advantages). The production chain with the medium technological production level, in which the use of production inputs was intensive, suffered more penalizing effects of taxation policies than the chains showing lower indices of modern input adoption, according to the values of Private Cost Ratios (PCRs), which were the following: 0.72, 0.46, and 0.26, for medium, low and high technological raw material production levels, respectively.
\end{abstract}

Key words: Policy Analysis Matrix; milk agribusiness; economic indicators; technological levels; public policies. 


\section{Introdução}

O mercado mundial de leite em pó apresenta grande importância para o Brasil, pois, por exemplo, em 2012, o país ocupava a quarta colocação na produção mundial $(12,4 \%)$, a segunda colocação no consumo mundial $(19,9 \%)$ e a terceira colocação nas importações $(7,5 \%)$. Por outro lado, as exportações não são representativas (United States Department of Agriculture [USDA], 2012). Esse produto respondeu por $60,1 \%$ das importações de produtos lácteos realizadas pelo Brasil em 2012 (Carneiro \& Siqueira, 2013).

Mesmo o leite em pó integral sendo o principal produto lácteo comercializado no mercado mundial e apresentando particular relevância para a balança comercial brasileira, existem poucos estudos relativos à competitividade das cadeias produtivas do leite em pó integral (em âmbito nacional e internacional), em particular, pesquisas que contemplem os preços pagos e recebidos pelos principais agentes econômicos envolvidos nas transações.

Este estudo teve como objetivo analisar a competitividade de três cadeias produtivas do leite em pó integral no Rio Grande do Sul, com três diferentes níveis tecnológicos (baixo, médio e alto) no elo de produção de matéria-prima, à luz da Policy Analysis Matrix (PAM). Para efeitos deste estudo, consideraram-se as diferentes tipologias estabelecidas a partir das diretrizes consideradas por Calegar (2001), que estabeleceu diferentes níveis de adoção de tecnologia para os sistemas agrícolas de produção de leite no Brasil.

A Policy Analysis Matrix (PAM) representa uma das principais ferramentas para a análise da competitividade de cadeias produtivas agrícolas, pois permite identificar os incentivos ou desincentivos aos agentes econômicos, conhecer os efeitos de políticas públicas sobre a lucratividade privada e examinar os impactos favoráveis ou desfavoráveis à sociedade relativos às atividades econômicas (Lopes et al., 2012; Monke \& Pearson, 1989; Vieira, Teixeira, Oliveira, \& Lopes, 2001).

Vale ressaltar que, nesta pesquisa, adotou-se o conceito de competitividade utilizado por Haguenauer (2012), em que competitividade é a "capacidade de uma indústria (ou empresa) produzir mercadorias com padrões de qualidade específicos, requeridos por mercados determinados, utilizando recursos em níveis iguais ou inferiores aos que prevalecem em indústrias semelhantes no resto do mundo, durante certo período de tempo" (p. 22).

Esta pesquisa amplia a fronteira do conhecimento relacionada à operacionalização dessa ferramenta, ao considerar na análise os diferentes elos das cadeias produtivas - uma abordagem ainda pouco desenvolvida - e o conhecimento da competividade de uma cadeia produtiva emergente do setor processador de laticínios. De fato, o único estudo brasileiro com a PAM sobre o leite em pó foi desenvolvido por Martins (2002).

\section{Referencial Teórico}

A Policy Analysis Matrix (PAM) foi desenvolvida a partir de 1981 por pesquisadores da University of Arizona e da University of Stanford no intuito de estudar as mudanças nas políticas agrícolas em Portugal. Com o passar dos anos, essa parceria entre os pesquisadores resultou na publicação do livro The Policy Analysis Matrix for Agricultural Development, em 1989 (Monke \& Pearson, 1989). Desde então, essa ferramenta difundiu-se como uma abordagem significativa para a análise da competitividade de cadeias produtivas agrícolas (Bernal, Lara-Herrera, Reyes-Rivas, \& Perez-Veyna, 2012; Currid-Halkett \& Stolarick, 2011; Monke \& Pearson, 1989; Picazo-Tadeo \& Wall, 2011; Soares, Silva, Rezende, Jacovine, \& Valverde, 2013; Sousa, Soares, Cordeiro, \& Silva, 2011; Zheng, Lambert, Wang, \& Wang, 2013). 
Nesse contexto, a PAM possui relevância em âmbito mundial em razão da aplicabilidade e contribuições para a sociedade, conforme estudos como os de: Barrera-Rodriguez, Jaramillo-Villanueva, Escobedo-Garrido e Herrera-Cabrera (2011), que estudaram o sistema de produção de baunilha no México, cujos resultados apontaram para uma desproteção do sistema produtivo, porém este se mostrou competitivo e com eficiência; Bobadilla-Soto, Espinoza-Ortega e Martínez-Castañeda (2013) analisaram a produção de suínos no México e verificaram que havia rentabilidade; Katic, Namara, Hope, Owusu e Fujii (2013), que estudaram o sistema de produção de arroz na África, cujos resultados evidenciaram que a intervenção do governo não melhorou significativamente a rentabilidade da produção de arroz devido ao efeito de falhas de mercado; Mane-Kapaj, Kapaj, Chan-Halbrendt e Totojani (2010), que avaliaram a vantagem comparativa da produção de azeite na Albânia, cujos resultados indicaram rentabilidade, porém o país não tem uma vantagem comparativa, sendo necessário obter uma maior produtividade; Martin e Noordwijk (2011), que analisaram os sistemas produtivos consorciados como alternativa econômica para pequenos agricultores nas Filipinas, cujos resultados indicaram rentabilidade, bem como uma tendência atual forte em políticas de preços para a produção de alimentos; Rastegaripour, Tavassoli, Rastegaripour, Piri e Karbasi (2011), que analisaram a vantagem comparativa da produção de água potável engarrafada no Irã, cujos resultados indicaram que existia vantagem comparativa; Sabaouhi, Ghanbari, Rastegaripour, Tavassoli e Esmaeilian (2011), que avaliaram as vantagens econômicas e relativas de consórcio de milho e feijão no Irã, cujos resultados mostraram que não havia vantagem relativa, mas o sistema de consórcio poderia aumentar os benefícios econômicos e de vantagens relativas; Sirajuddin et al. (2013), que analisaram a vantagem comparativa da produção de leite fresco na Indonésia, cujos resultados mostraram que a produção não era tão competitiva e possuía menos rentabilidade, constatando-se, por fim, que a política atual do governo não favoreceu os agricultores locais.

No âmbito de estudos relacionados ao leite em pó integral, Guba (2000) desenvolveu um estudo dedicado ao elo de industrialização do leite em pó integral na Polônia, em 1997. A pesquisa mostrou que havia competitividade em relação ao lucro privado auferido pela atividade econômica; além do mais, o produto não sofria penalizações e estava gerando ganhos, fato que foi observado por meio do Coeficiente de Proteção Nominal (CPN).

Feitas essas considerações, o artigo baseou-se na abordagem da PAM sobre o enfoque da competitividade utilizado por Haguenauer (2012). Nesse sentido, a PAM possui legitimidade em contexto científico, traz contribuições relevantes ao entendimento do desempenho econômico no que envolve questões relacionadas com custos, receitas operacionais e rentabilidade, bem como contribui no avanço de estudos sobre competitividade em países em desenvolvimento. Por fim, vale ressaltar que, no Brasil, os pesquisadores da Empresa Brasileira de Pesquisa Agropecuária (EMBRAPA) e da Fundação Getúlio Vargas (FGV) realizaram adaptações no método com o intuito de atender às particularidades e especificidades dos sistemas produtivos agrícolas brasileiros.

\section{Material e Métodos}

\section{Delimitação e caracterização do estudo}

As cadeias produtivas foram adaptadas e categorizadas conforme as diretrizes estabelecidas por Calegar (2001). Neste caso, adotaram-se três níveis: (a) Cadeia Produtiva do Leite em Pó Integral, tipo I, com nível tecnológico baixo no elo da produção de leite (CPLEI-I); (b) Cadeia Produtiva do Leite em Pó Integral, tipo II, com nível tecnológico médio no elo da produção de leite (CPLEI-II); e (c) Cadeia Produtiva do Leite em Pó Integral, tipo III, com nível tecnológico alto no elo da produção de leite (CPLEI-III), conforme as características de cada sistema de produção, apresentados na Tabela 1. 
Tabela 1

\section{Principais Características dos Níveis Tecnológicos das Cadeias Produtivas Analisadas}

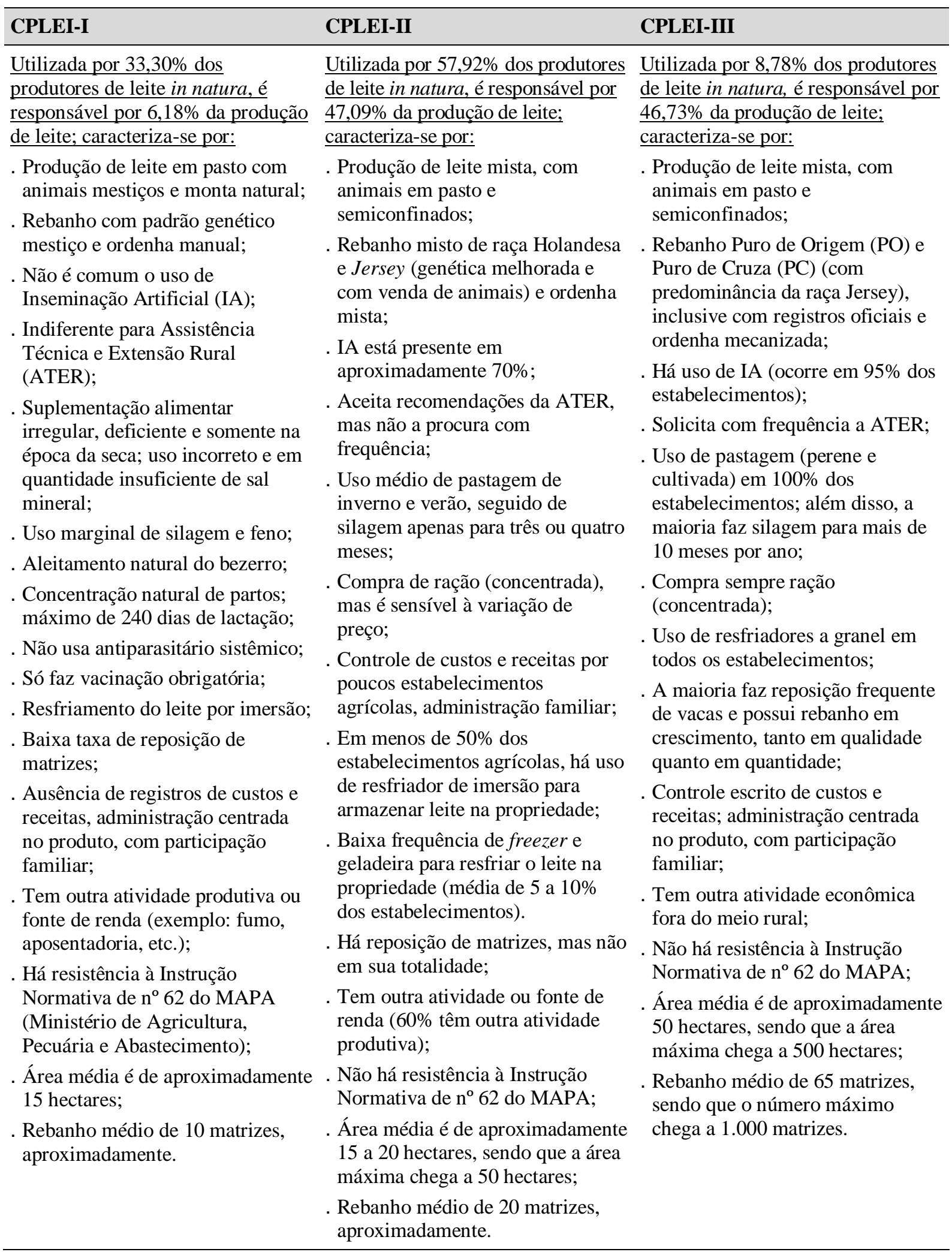

Nota. CPLEI-I: Cadeia Produtiva do Leite em Pó Integral, tipo I, com nível tecnológico baixo no elo da produção; CPLEIII: Cadeia Produtiva do Leite em Pó Integral, tipo II, com nível tecnológico médio no elo da produção; CPLEI-III: Cadeia Produtiva do Leite em Pó Integral, tipo III, com nível tecnológico alto no elo da produção. Fonte: Elaborado pelos autores. 
Essa caracterização foi elaborada considerando o universo dos cooperados da cooperativa parceira nesta pesquisa, que correspondem a 3.372 unidades produtoras de leite, sendo 1.123 da CPLEI-I, 1.953 da CPLEI-II e 296 da CPLEI-III, localizadas na mesorregião do sudeste rio-grandense, cuja unidade de beneficiamento está situada no município de Pelotas/RS. Nesse contexto, foi selecionado um estabelecimento representativo para cada cadeia produtiva. Tais estabelecimentos são compreendidos como os produtores que devem estar no intervalo do benchmark do setor, próximo do nível de excelência nas escalas técnicas e econômicas (Lopes et al., 2012). Assim, cada categoria foi realizada a partir do auxílio técnico de pesquisadores da Embrapa e técnicos da cooperativa estudada.

A equipe foi composta por quatro gerentes (fomento, finanças, industrial e logístico) que atuaram na coleta dos dados industriais e comerciais da cooperativa parceira, e também contou com a participação de engenheiros (de produção e agrônomo), um técnico agropecuário e um assistente social, que atuaram na coleta de dados no campo, junto aos quatro proprietários dos estabelecimentos representativos. Por fim, três pesquisadores da Embrapa participaram na aplicação e análise dos dados da PAM.

Sobre a caracterização dos quatro elos que compõem cada cadeia, verifica-se que o primeiro elo é o de produção do leite in natura. São considerados cada nível de adoção de tecnologia descrito anteriormente (baixo, médio e alto). Os demais elos das cadeias são comuns, isto é, o nível de tecnologia não interfere: o segundo elo é o de transporte do leite in natura até a agroindústria; o terceiro elo é o de processamento na agroindústria do leite in natura em leite em pó integral; por fim, o quarto elo é o de transporte do leite em pó integral de Pelotas/RS até São Paulo/SP (Figura 1). Assim, as cadeias apresentam características de desempenho diferentes em função da variação da tecnologia empregada pelos agricultores e dos rendimentos ou volume de produção.

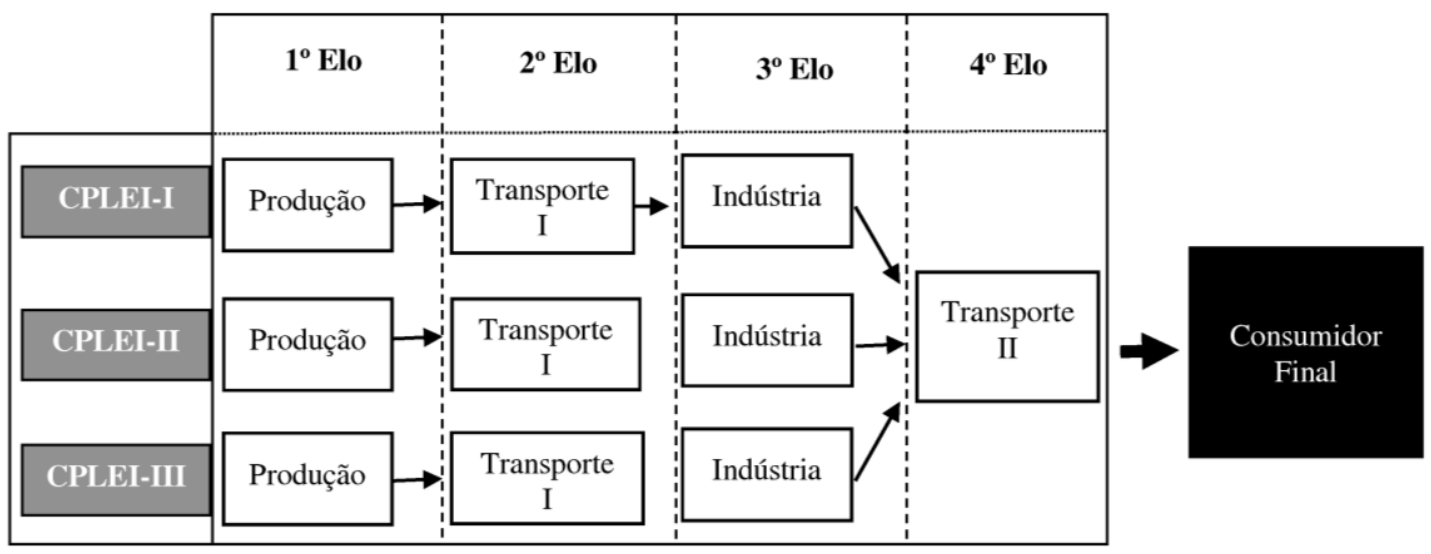

Figura 1. Estrutura das Cadeias Produtivas de Leite em Pó Integral Analisadas na Pesquisa

$\mathbf{1}^{\circ}$ Elo: Produção do leite in natura; $\mathbf{2}^{\mathbf{0}}$ Elo: Transporte do leite in natura até a agroindústria; $\mathbf{3}^{\mathbf{0}}$ Elo: Processamento na agroindústria do leite in natura em leite em pó integral; $\mathbf{4}^{\mathbf{0}}$ Elo: Transporte do leite em pó integral de Pelotas/RS até São Paulo/SP; CPLEI-I: Cadeia Produtiva do Leite em Pó Integral, tipo I, com nível tecnológico baixo no elo da produção; CPLEIII: Cadeia Produtiva do Leite em Pó Integral, tipo II, com nível tecnológico médio no elo da produção; CPLEI-III: Cadeia Produtiva do Leite em Pó Integral, tipo III, com nível tecnológico alto no elo da produção. Fonte: Elaborado pelos autores.

O Rio Grande do Sul foi escolhido em função dos seguintes elementos: a disponibilidade de dados que contemplam a cadeia produtiva do leite em pó integral; a acessibilidade aos agentes de cada elo; a relevância na produção nacional de leite; e o nível de produtividade, já que o estado possui a maior produtividade, com 2.430 litros/vaca/ano (Instituto Brasileiro de Geografia e Estatística [IBGE], n.d.a, 2013c). Além do mais, a atividade leiteira tem uma grande importância social na geração de emprego e renda na economia agrícola gaúcha.

A caracterização dos dados ocorreu em função de sua natureza, ou seja, dados primários e secundários. Os dados secundários, utilizados para caracterizar os indicadores socioeconômicos das cadeias produtivas, tiveram várias fontes oficiais e fidedignas (Carneiro \& Siqueira, 2013; Centro de Estudos Avançados em Economia Aplicada - Escola Superior de Agricultura Luiz de Queiroz/Universidade de São Paulo - Confederação da Agricultura e Pecuária do Brasil [Cepea- 
Esalq/USP-CNA], 2013; Centro de Orientação Fiscal [CENOFISCO], 2012; Food and Agriculture Organization of the United Nations [FAO], 2013; IBGE, n.d.a, n.d.b, n.d.c).

Os dados primários foram coletados com o auxílio de planilhas integradas ambientadas no editor Excel da Microsoft, que são de dupla entrada para as despesas (incluindo impostos), receitas e lucros privados e sociais. Essa estrutura econômico-financeira de organizar dados e de contabilidade completa da cadeia produtiva permite, respectivamente, obter resultados finais com e sem as divergências entre preços privados e sociais, constituídas pelas distorções, as quais são representadas pelas tributações e impostos, gravames governamentais (administração de preços, por exemplo) e falhas de mercado. Para isso, as planilhas apresentam os fatores de conversão, os quais representam a porcentagem que converte/altera o preço privado em preço social, exatamente devido aos impostos e custo de oportunidade existentes nos preços correntes (preço privado).

Os dados foram coletados entre os meses de abril e junho de 2013, e os preços efetivamente pagos (despesas) e recebidos (receitas) nas cadeias produtivas correspondem ao ano de 2012, sendo empregadas as unidades de preço por hectare no $1^{\circ}$ Elo e de preço por tonelada nos outros três elos. Para os dados da CPLEI-I, que são os de menor nível de uso de insumos com tecnologia, os registros contábeis foram coletados considerando as estimativas do proprietário do estabelecimento produtor de leite e de um técnico agrícola da cooperativa.

\section{Delimitação e caracterização do método da Policy Analysis Matrix (PAM)}

O método adotado seguiu as diretrizes apresentadas em Monke e Pearson (1989) e consiste em um instrumento contábil que dá consistência para a análise das políticas econômicas. Os objetivos foram obter indicadores de competitividade e apresentar a existência de vantagens comparativas entre cadeias produtivas agrícolas de diferentes níveis de uso de insumos, bem como analisar a eficiência econômica expressa pelos preços sociais ou aqueles preços que deveriam existir, pois representam o verdadeiro e real desempenho da cadeia produtiva, sem as interferências de impostos ou falhas de mercado, não corrigidos por políticas. Além desses dois aspectos econômicos, avaliou-se o impacto de políticas diretas e indiretas no setor. Estas políticas podem ser fiscais, tecnológicas (aspecto enfatizado neste estudo), ambientais e outras medidas governamentais, como por exemplo, taxação, subsídios, restrições comerciais e distorções na taxa de câmbio (Monke \& Pearson, 1989).

Além disso, a PAM permitiu desenvolver estudos de análise de sensibilidade ou simulações com diferentes variações nos componentes de despesa e receita que mais impactam no lucro do produto, seja sobre: o preço dos insumos que compõem os custos de produção, o preço pago ao produto final, a taxa de câmbio, volume ou rendimento da produção e tributos (redução/elevação de alíquotas).

Assim, no intuito de ampliar o escopo da análise sobre a competitividade, neste estudo, foi realizada uma simulação com a variável preço. Logo, é importante explicitar que, para essa simulação, adotou-se um cenário de redução de $10 \%$ no preço pago ao produtor pelo leite em pó integral, de modo que o critério seguido na escolha desse cenário foi arbitrado de forma intencional, visto que é uma prática comum em estudos que adotam o método PAM.

Sobre a estrutura da matriz, os dados que compõem a PAM são categorizados em duas vertentes: preços privados (correspondem aos preços estabelecidos pelas leis do mercado, sendo representados por valor monetário vigente e obtidos por meio de uma cotação em mercado local) e preços sociais (valor monetário vigente, obtido por meio de uma cotação em mercado internacional, ou considerado o custo de oportunidade, que envolve a atividade econômica e a retirada dos impostos incidentes sobre os preços pagos e recebidos) (Monke \& Pearson, 1989).

As vertentes apresentam os seguintes valores (Tabela 2): receita operacional, que é o somatório de todos os rendimentos oriundos do objeto de exploração da organização; custos de produção, que são o somatório de todos os gastos ligados ao processo de produção; e lucros, representados por D, H e L, expressos na forma de ganhos ao final de todas as operações produtivas dentro da cadeia. 
Tabela 2

\section{Representação Teórica da Matriz Contábil de Análise da Policy Analysis Matrix (PAM)}

\begin{tabular}{lcccc}
\hline & \multirow{2}{*}{ RECEITA } & \multicolumn{2}{c}{ CUSTOS DE PRODUÇÃO } & \multirow{2}{*}{ LUCROS } \\
\cline { 3 - 4 } & & Insumos comercializáveis & Fatores domésticos & \\
\hline Preços Privados & $\mathrm{A}$ & $\mathrm{B}$ & $\mathrm{C}$ & $\mathrm{D}$ \\
Preços Sociais & $\mathrm{E}$ & $\mathrm{F}$ & $\mathrm{G}$ & $\mathrm{H}$ \\
$\begin{array}{l}\text { Efeito de divergências e } \\
\text { eficiência de políticas }\end{array}$ & $\mathrm{I}$ & $\mathrm{J}$ & $\mathrm{K}$ & $\mathrm{L}$ \\
\hline
\end{tabular}

Nota. A: Receita da cadeia produtiva estudada a preços privados; B: Insumos gastos na cadeia produtiva estudada a valores privados; C: Fatores de produção gastos na cadeia produtiva estudada a valores privados; D: Lucro privado da cadeia produtiva estudada; E: Receita da cadeia produtiva sobre paridade internacional (receita a preços sociais); F: Insumos comercializáveis gastos na cadeia produtiva sobre paridade internacional; G: Fatores domésticos gastos na cadeia produtiva sobre paridade internacional; H: Lucro da cadeia produtiva estudada sobre paridade internacional; I: Transferências de receitas = A - E; J: Transferências de insumos = B - F; K: Transferências de fatores = C - G; L: Transferências líquidas = D - H ou I - J - K. Nos sobrescritos relacionados a seguir, o $d$ indica que o valor da variável é observado (preço de mercado), e o sobrescrito $s$ é para indicar a valoração social do parâmetro. $\mathbf{A}=\mathrm{p}^{\mathrm{d}} \mathrm{q}^{\mathrm{d}}$, receita privada, em que $\mathrm{p}^{\mathrm{d}}$ : preço privado do produto; $\mathrm{q}^{\mathrm{d}}$ : quantidade total do produto; $\mathbf{B}=\sum \mathrm{p}_{\mathrm{j}} \mathrm{q}_{\mathrm{j}}^{\mathrm{d}}$, custo privado dos insumos comercializáveis, em que $\mathrm{p}_{\mathrm{j}}^{\mathrm{d}}$ : preço privado do insumo $\mathrm{i} ; \mathrm{q}_{\mathrm{j}} \mathrm{d}_{\mathrm{j}}^{\mathrm{d}}$ quantidade do insumo i utilizado; $\mathbf{C}=\sum \mathrm{w}_{\mathrm{j}}^{\mathrm{d}} \mathrm{l}_{\mathrm{j}}^{\mathrm{d}}$, custo privado dos insumos domésticos, em que $\mathrm{w}_{\mathrm{j}}^{\mathrm{d}}$ : preço privado do insumo $\mathrm{j} ; \mathrm{l}_{\mathrm{j}}^{\mathrm{d}}$ : quantidade do insumo j utilizado; $\mathbf{D}=\partial^{\mathrm{d}}$, lucratividade privada $=\mathrm{A}-\mathrm{B}-\mathrm{C} ; \mathbf{E}=\mathrm{p}^{\mathrm{s}} \mathrm{q}^{\mathrm{s}}$, receita social, em que $\mathrm{p}^{\mathrm{s}}$ : preço social do produto; $\mathrm{q}^{\mathrm{s}}$ : quantidade total do produto; $\mathbf{F}=\sum \mathrm{p}_{\mathrm{i}}^{\mathrm{s}} \mathrm{q}_{\mathrm{i}}^{\mathrm{s}}$, custo social de insumo comercializável, em que $\mathrm{p}_{\mathrm{i}}^{\mathrm{s}}$ : preço social de insumo i; $\mathrm{q}_{\mathrm{i}}^{\mathrm{s}}$ : quantidade de insumo i utilizado; $\mathbf{G}=\sum \mathrm{w}_{\mathrm{j}}^{\mathrm{s}} \mathrm{l}_{\mathrm{j}}^{\mathrm{s}}$, custo social de insumo doméstico, em que $\mathrm{w}_{\mathrm{i}}^{\mathrm{s}}$ : preço social de insumo $\mathrm{j} ; 1_{j}^{\mathrm{s}}$ : quantidade de insumo j utilizado; $\mathbf{H}=\partial^{\mathrm{s}}$, lucratividade social $=\mathrm{E}-\mathrm{F}-\mathrm{G} ; \mathbf{I}$, transferências associadas à produção $=\mathrm{A}-\mathrm{E} ; \mathbf{J}$, transferências associadas ao custo dos insumos comercializáveis = B - F; K, transferências associadas ao custo dos fatores domésticos = C- G; L, transferências líquidas = D- H ou = I- J- K. Fonte: Adaptado de Monke, E. A., \& Pearson, S. R. (1989). The Policy Analysis Matrix for agricultural development (pp. 15-16). New York: Cornell University Press.

Vale ressaltar que os custos de produção foram classificados em duas categorias: insumos comercializáveis, que correspondem à matéria-prima (inputs) utilizada no processo de produção, e fatores domésticos, que correspondem aos recursos de produção, contemplando terra, capital e trabalho (Monke \& Pearson, 1989).

Os preços privados deste estudo contemplam os valores referentes às três cadeias em análise, os quais correspondem aos seguintes dados contábeis: as receitas operacionais, os custos de produção, e os lucros das cadeias produtivas. A categoria preços sociais possui a mesma estrutura de dados (receita operacional, custos de produção e lucro). Contudo, esses dados são considerados como fator de paridade, tido como situação em que se opera sem a intervenção do Estado no que concerne à presença de políticas, como: tributárias (impostos), monetárias (juros e câmbio), trabalhistas (encargos), fiscais (subsídios) e as políticas de comércio exterior (impostos de exportação e importação, tarifas, etc.) (Vieira et al., 2001).

Portanto, na operacionalização da PAM (Tabela 2), a primeira identidade da matriz é formada pelos valores representados pelas letras A, B, C e D, referindo-se aos valores de mercado correspondentes às cadeias produtivas estudadas. A segunda identidade é formada pelas letras $\mathrm{E}, \mathrm{F}, \mathrm{G} \mathrm{e}$ $\mathrm{H}$, referindo-se aos valores de preços sociais das cadeias produtivas na paridade internacional ou sem a interferência de tributos. Já a terceira identidade da matriz contábil é formada pelas letras I, J, K e L, que são os elementos referentes às diferenças ou divergências entre os valores privados e sociais de receitas, custos e lucros.

Sobre a composição dos dados que formam a PAM, torna-se necessário esclarecer que se adotou a metodologia de Lopes et al. (2012) para catalogar os valores privados e sociais que contemplam cada cadeia produtiva, de modo que, em cada um dos quatros elos (Figura 1), foram mensurados os custos fixos, custos dos fatores, custos dos insumos, custos totais, receitas totais e lucros.

Sobre os indicadores quantitativos da PAM (Tabela 3), estes podem ser utilizados para diversas análises, isto é, análise de lucratividade, análise de eficiência, análise de proteção e análise da transferência de políticas (Monke \& Pearson, 1989). 
Tabela 3

\section{Representação Teórica dos Principais Aspectos da Policy Analysis Matrix (PAM) Referentes aos Indicadores, Finalidade e Interpretação dos Resultados}

\begin{tabular}{|c|c|c|}
\hline INDICADOR & FINALIDADE & RESULTADO \\
\hline $\begin{array}{c}\text { Lucro Privado } \\
(\mathbf{L P})=\mathrm{A}-\mathrm{B}-\mathrm{C}\end{array}$ & $\begin{array}{l}\text { Mede a rentabilidade econômica da cadeia } \\
\text { produtiva indicando se há competitividade na } \\
\text { atividade desenvolvida, dadas as tecnologias e } \\
\text { dados os valores e os custos de produção. }\end{array}$ & $\begin{array}{l}\text { Para } L P>0 \text { : os agentes estão auferindo } \\
\text { lucros. Para } \mathrm{LP}<0 \text { : os agentes estão tendo } \\
\text { prejuízo. Para } \mathrm{LP}=0 \text { : os agentes não estão } \\
\text { recebendo lucro nem tendo prejuízo. }\end{array}$ \\
\hline $\begin{array}{c}\text { Lucro Social } \\
(\mathbf{L S})=\mathrm{E}-(\mathrm{F}+\mathrm{G})\end{array}$ & $\begin{array}{l}\text { Mede a eficiência econômica do produto } \\
\text { obtido nas cadeias produtivas e revela a } \\
\text { vantagem comparativa, pois, para o cálculo, } \\
\text { é considerado o custo de oportunidade, que } \\
\text { envolve a atividade econômica e a retirada } \\
\text { dos impostos incidentes sobre os preços } \\
\text { pagos e recebidos ou pode ser obtido por } \\
\text { meio de uma cotação em mercado }\end{array}$ & $\begin{array}{l}\text { Para } L S>0 \text { : a cadeia produtiva gastará } \\
\text { recursos para a produção a preços sociais } \\
\text { que ficarão aquém dos privados. Para } L S<0 \text { : } \\
\text { os recursos ficarão além dos custos privados. } \\
\text { Para } L S=0 \text { : a cadeia produtiva não } \\
\text { desperdiçou recursos de produção, nem teve } \\
\text { os gastos superiores aos custos privados. }\end{array}$ \\
\hline
\end{tabular}
internacional.

\begin{tabular}{|c|c|c|}
\hline $\begin{array}{l}\text { Transferência } \\
\text { Líquida de } \\
\text { Políticas } \\
\text { (TLP) = D-H ou } \\
(\text { TLP) }=\text { I-J-K }\end{array}$ & $\begin{array}{l}\text { Calcula os efeitos de divergências entre o } \\
\text { lucro privado e o lucro social, como } \\
\text { resultado da ineficiência das políticas } \\
\text { tecnológicas e tributárias que estão incidindo } \\
\text { sobre as cadeias produtivas, estudadas para } \\
\text { evidenciar os impactos das inovações sobre } \\
\text { competitividade, eficiência econômica e } \\
\text { efeitos da tributação em cada uma delas. }\end{array}$ & $\begin{array}{l}\text { Para TLP }>0 \text { : o governo transferiu à cadeia } \\
\text { produtiva, por meio de políticas públicas, } \\
\text { certo valor monetário. Para TLP }<0 \text { : o } \\
\text { governo transferiu da cadeia, por meio de } \\
\text { políticas públicas, certo montante de renda. } \\
\text { Para TLP = 0: sem transferência de renda } \\
\text { para a sociedade ou para a cadeia produtiva. }\end{array}$ \\
\hline $\begin{array}{l}\text { Razão do Custo } \\
\text { Privado } \\
(\mathbf{R C P})=\mathrm{C} /(\mathrm{A}-\mathrm{B})\end{array}$ & $\begin{array}{l}\text { Serve para medir quanto de renda é } \\
\text { necessário para que a cadeia produtiva } \\
\text { compense os pagamentos dos fatores } \\
\text { domésticos (terra, capital e trabalho) e ainda } \\
\text { permaneça competitiva. }\end{array}$ & $\begin{array}{l}\text { Para } \mathrm{RCP}>1 \text { : a cadeia produtiva não } \\
\text { consegue remunerar os fatores domésticos e } \\
\text { manter-se competitiva. Para } \mathrm{RCP}<1 \text { : a } \\
\text { cadeia produtiva consegue remunerar os } \\
\text { fatores domésticos e manter-se competitiva. }\end{array}$ \\
\hline $\begin{array}{c}\text { Razão dos } \\
\text { Custos dos } \\
\text { Recursos } \\
\text { Domésticos } \\
\text { (RCD) }=\mathrm{G} /(\mathrm{E}-\mathrm{F})\end{array}$ & $\begin{array}{l}\text { Serve para medir a vantagem comparativa da } \\
\text { cadeia produtiva, isto é, o quanto é } \\
\text { necessário alocar de recursos domésticos } \\
\text { para obter de retorno } \mathrm{R} \$ 1,00 \text {, seja para } \\
\text { economizar (ao importar), seja para gerar (ao } \\
\text { exportar). }\end{array}$ & $\begin{array}{l}\text { Para } R C D>1 \text { : a cadeia produtiva não } \\
\text { consegue ser competitiva, e o uso dos fatores } \\
\text { não é suficiente para economizar em real } \\
\text { brasileiro }(\mathrm{R} \$ \text { ) de divisas. Para } \mathrm{RCD}<1: \text { a } \\
\text { cadeia produtiva consegue ser competitiva, e } \\
\text { o uso dos fatores é suficiente para economizar } \\
\text { em real brasileiro }(\mathrm{R} \$) \text { de divisas. }\end{array}$ \\
\hline $\begin{array}{l}\text { Coeficiente de } \\
\text { Proteção } \\
\text { Nominal } \\
(\mathrm{CPN})=\mathrm{A} / \mathrm{E}\end{array}$ & $\begin{array}{l}\text { Estima a proteção ou tributação das cadeias } \\
\text { no mercado de produtos e permite a } \\
\text { comparação entre os preços privados e } \\
\text { sociais recebidos pelo produto final. }\end{array}$ & $\begin{array}{l}\text { Para } C P N>1 \text { : há proteção, e o produtor } \\
\text { recebe um valor superior a preços de } \\
\text { mercado. Para } C P N<1 \text { : há desproteção, e o } \\
\text { produtor recebe um valor inferior a preços } \\
\text { de mercado. Para } C P N=1 \text { : indica que não há } \\
\text { transferência de renda na cadeia. }\end{array}$ \\
\hline $\begin{array}{l}\text { Coeficiente de } \\
\text { Proteção Efetiva } \\
\begin{array}{c}\text { (CPE) }=(\mathrm{A}- \\
\mathrm{B}) /(\mathrm{E}-\mathrm{F})\end{array}\end{array}$ & $\begin{array}{l}\text { Estima o nível de proteção ou de taxação } \\
\text { sobre o produto final e os insumos } \\
\text { comercializáveis que o compõem. }\end{array}$ & $\begin{array}{l}\text { Para CPE>1: o produtor está sendo } \\
\text { beneficiado com a presença das políticas de } \\
\text { intervenção nos mercados do produto e de } \\
\text { insumos comercializáveis. Para CPE<1: o } \\
\text { produtor pode estar sendo penalizado, pois } \\
\text { há benefício na importação. Para CPE=1: } \\
\text { indica que não há proteção ou desproteção } \\
\text { sobre o produto final e os insumos } \\
\text { comercializáveis que o compõem. }\end{array}$ \\
\hline
\end{tabular}




\section{Tabela 3 (continuação)}

\begin{tabular}{|c|c|c|}
\hline INDICADOR & FINALIDADE & RESULTADO \\
\hline $\begin{array}{c}\text { Coeficiente de } \\
\text { Lucratividade } \\
\text { (CL) }=(\mathrm{A}-\mathrm{B}- \\
\mathrm{C}) /(\mathrm{E}-\mathrm{F}-\mathrm{G}) \text { ou } \\
\mathrm{D} / \mathrm{H}\end{array}$ & $\begin{array}{l}\text { Permite dimensionar a diferença em termos } \\
\text { numéricos (valor em R\$) entre o LP e o LS, } \\
\text { apresentando, assim, o lucro que se obteria } \\
\text { na ausência de políticas causadoras de } \\
\text { distorção, ou lucro sem a transferência } \\
\text { líquida resultante da intervenção de políticas } \\
\text { na cadeia, na forma de protecionismo ou } \\
\text { taxação. }\end{array}$ & $\begin{array}{l}\text { Para CL>1: o produtor está sendo } \\
\text { beneficiado, isto é, há protecionismo na } \\
\text { cadeia produtiva. Para CL<1: o produtor não } \\
\text { está sendo beneficiado, isto é, não há } \\
\text { protecionismo na cadeia produtiva. Para } \\
C L=1 \text { : a cadeia produtiva não tem } \\
\text { interferência de protecionismo, tampouco de } \\
\text { taxação; situação neutra. }\end{array}$ \\
\hline $\begin{array}{c}\text { Razão de } \\
\text { Subsídio aos } \\
\text { Produtores } \\
\text { (RSP) }=\text { L/E ou } \\
\text { (D-H) } / \mathrm{E}\end{array}$ & $\begin{array}{l}\text { Permite mostrar o quanto, em termos de } \\
\text { valores sociais, é necessário para manter a } \\
\text { eficiência econômica da cadeia produtiva, } \\
\text { considerando incrementos de políticas } \\
\text { macroeconômicas. }\end{array}$ & $\begin{array}{l}\text { Para RSP }>1 \text { : na cadeia produtiva, há } \\
\text { presença de subsídios. Para RSP<1: na } \\
\text { cadeia produtiva, não há presença de } \\
\text { subsídios, e sim de taxação. Para RSP=1: a } \\
\text { cadeia produtiva não sofre interferência de } \\
\text { protecionismo, tampouco de taxação; } \\
\text { situação neutra. }\end{array}$ \\
\hline
\end{tabular}

Nota. A: Receita da cadeia produtiva estudada a preços privados; B: Insumos gastos na cadeia produtiva estudada a valores privados; C: Fatores de produção gastos na cadeia produtiva estudada a valores privados; D: Lucro privado da cadeia produtiva estudada; E: Receita da cadeia produtiva sobre paridade internacional (receita a preços sociais); F: Insumos comercializáveis gastos na cadeia produtiva sobre paridade internacional; G: Fatores domésticos gastos na cadeia produtiva sobre paridade internacional; H: Lucro da cadeia produtiva estudada sobre paridade internacional; I: Transferências de receitas = A - E; J: Transferências de insumos = B - F; K: Transferências de fatores = C - G; L: Transferências líquidas = D - H ou I - J - K; LP: Lucro Privado; LS: Lucro Social; TLP: Transferência Líquida de Políticas; RCP: Razão do Custo Privado; RCD: Razão dos Recursos Domésticos; CPN: Coeficiente de Proteção Nominal; CPE: Coeficiente de Proteção Efetiva; CL: Coeficiente de Lucratividade; RSP: Razão de Subsídio aos Produtores. Fonte: Elaborado pelos autores.

\section{Resultados e Discussão}

A discussão dos resultados está organizada em cinco seções: Análise de lucratividade, Análise de eficiência, Análise de proteção, Análise da transferência de políticas e, por fim, Simulação da variável preço.

\section{Análise de lucratividade}

$\mathrm{Na}$ Tabela 4, encontram-se os resultados da PAM referentes à análise de lucratividade para os três diferentes níveis tecnológicos (baixo, médio e alto) nas cadeias produtivas do leite em pó integral localizadas no Estado do Rio Grande do Sul, Brasil. 
Tabela 4

Lucratividade e Divergências de Preços nas Cadeias Produtivas de Leite em Pó Integral no Rio Grande do Sul - Brasil, Calculadas pelo Método da PAM em R\$/Tonelada

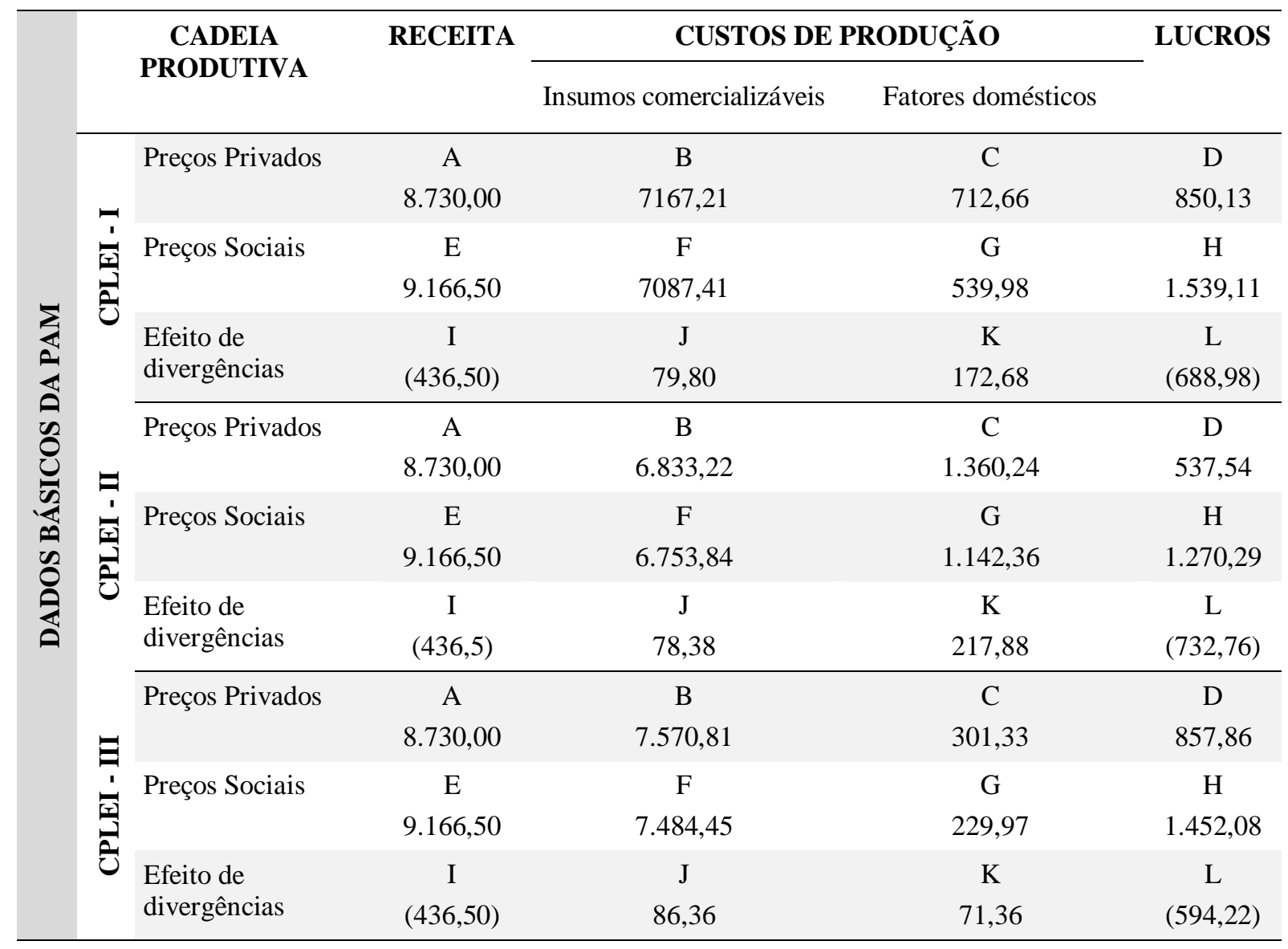

Nota. Fonte: Elaborado pelos autores.

Quanto ao Lucro Privado (LP), verificou-se que há rentabilidade positiva para as três cadeias produtivas estudadas, independentemente do nível de adoção de tecnologia, pois os resultados por tonelada de leite em pó integral foram: CPLEI-III: R\$ 857,86; CPLEI-I: R\$ 850,13; e CPLEI-II $\mathrm{R} \$ 537,54$. Isso indica a rentabilidade econômica das cadeias produtivas estudadas.

Em termos comparativos, no que diz respeito aos custos de produção, houve superioridade dos custos privados relacionados aos insumos comercializáveis em relação aos fatores domésticos de produção, podendo-se inferir, então, que parte da competitividade das cadeias produtivas estava sensivelmente relacionada ao maior uso de insumos, assim como observado em outros setores da economia por meio de outras investigações, como as de Nelson e Panggabean (1991); Maithya, Kimenye, Mugivane e Ramisch (2006); e Bernal, Lara-Herrera, Reyes-Rivas e Perez-Veyna (2012). De modo geral, esses custos de produção, por sua vez, deveriam receber mais atenção por parte das políticas governamentais por possuírem impostos indiretos embutidos e pouco percebíveis pelos agentes da cadeia, onerando a competitividade privada (ou dessas cadeias) frente aos concorrentes internacionais.

Em síntese, os resultados dependeram, em grande parte, da isenção do ICMS sobre o leite in natura produzido (e processado) no Rio Grande do Sul, pois esse fator impacta de forma direta sobre a competitividade das cadeias produtivas consideradas no estudo. Do contrário, a alíquota do ICMS seria de $7 \%$ ou $12 \%$ sobre o leite in natura (CENOFISCO, 2012).

Quanto ao Lucro Social (LS), de acordo com a Tabela 4, os indicadores foram todos positivos, na seguinte ordem: CPLEI-I: R \$ 1.539,11; CPLEI-III: R \$ 1.452,08; e CPLEI-II: R \$ 1.270,29, por 
tonelada. Contudo, de forma geral, os resultados apontam para um quadro de desempenho positivo de cada cadeia produtiva, porém suas particularidades não asseguram que sejam homogêneos em relação à eficiência econômica. Portanto, os resultados indicam que as cadeias produtivas de leite em pó integral podem ser consideradas eficientes.

Quanto ao desempenho das cadeias, ao se considerar o LS, observou-se que a CPLEI-I (R \$ 1.539,11) apresentou uma melhor produtividade na alocação de recursos produtivos para obtenção do produto final, isto é, com base no LS, a CPLEI-I obteve uma performance equilibrada no uso dos inputs utilizados para produzir o leite em pó integral. Assim, essa cadeia obteve maior vantagem comparativa, visto que o lucro foi o maior entre as demais cadeias analisadas. Entretanto, a situação requer atenção especial, pois mesmo que a cadeia tenha consumido menos recursos para produção de uma tonelada de leite em pó integral, o desempenho produtivo está relacionado à atual capacidade em produzir - fator que está no limite.

Assim, comparando-se a CPLEI-I com as demais cadeias, viu-se que ela apresenta pouquíssimos incrementos em níveis tecnológicos destinados ao primeiro elo (a produção do leite in natura), o que contribuiu para um custo menor de produção - situação que justifica o resultado ser o maior entre os indicadores analisados para o LS.

Este resultado, por outro lado, expressa e confirma uma condição das distorções que a alta tributação provoca na eficiência econômica das cadeias agroindustriais, em virtude do excessivo peso dos impostos diretos e indiretos sobre os insumos agropecuários em geral. Esta condição confirma uma frequente observação de especialistas em análises econômicas de outras cadeias produtivas de alimentos e fibras no Brasil (Lopes et al., 2012), os quais afirmam que existe uma perversa contradição da atual política de preços incidentes sobre estes insumos, pois, de maneira geral, tem-se observado que quanto maior a tecnologia empregada, menor será o lucro social. Entretanto, os resultados da CPLEI-I reproduzem uma realidade do contexto da agricultura familiar, sistema de produção de subsistência ou que realiza a venda do excedente da produção de forma independente, sem integração com a agroindústria, o que não significa o melhor paradigma para o setor produtivo competitivo e sustentável. A hipótese de existência de eficiência econômica para o desenvolvimento dessa cadeia produtiva não assegura a sustentabilidade. Uma forma de estimular o desenvolvimento da CPLEI-I é promover um aumento de produtividade e a melhoria na qualidade do leite in natura entregue à cooperativa, o que possivelmente traria efeitos positivos, bem como a elevação no lucro privado.

Portanto, ao se comparar os valores dos indicadores de LS frente ao LP, verificou-se que todos os indicadores de $\mathrm{LP}_{\mathrm{S}}$ foram inferiores aos de $\mathrm{LS}_{\mathrm{s}}$. Isso indica que a presença de distorções no mercado contribuiu para a redução da competitividade do leite em pó integral das cadeias produtivas ou que, de modo mais específico, as políticas públicas penalizaram os produtores de leite, em virtude dos atuais níveis de tributação, taxa de câmbio, encargos sociais e outras políticas, comercial e setorial.

No que se refere ao Coeficiente de Lucratividade (CL), de acordo com a Tabela 5, verificou-se que todos os resultados dos Coeficientes de Lucratividade $\left(\mathrm{CL}_{S}\right)$ foram positivos e menores que a unidade (1), com os seguintes valores: CPLEI-III: 0,59; CPLEI-I: 0,55; e CPLEI-II: 0,42. Tais índices, ao se encontrarem no intervalo de 0,42 a 0,59 , indicam que as cadeias produtivas foram liquidamente taxadas e que os LPS foram reduzidos, comprometendo a lucratividade dos agentes privados na comercialização do leite em pó integral.

Tabela 5

Coeficientes de Lucratividade da Cadeia Produtiva do Leite em Pó Integral no Rio Grande do Sul, Brasil

\begin{tabular}{lccc}
\hline \multicolumn{1}{c}{ Indicadores privados e sociais } & CPLEI-I & CPLEI-II & CPLEI-III \\
\hline $\mathbf{C L}=\mathrm{D} / \mathrm{H}$ & 0,55 & 0,42 & 0,59 \\
\hline
\end{tabular}

Nota. Fonte: Elaborado pelos autores. 
A CPLEI-II apresentou o quadro mais grave. Seu CL foi de 0,42 , indicando que o LP foi reduzido em aproximadamente 58\%, ou seja, evidencia-se uma forte desproteção sobre a produção e comercialização do leite em pó integral. Em termos comparativos, o índice CPLEI-III $(0,59)$ apresentou o quadro menos grave, e isso indica que o LP foi reduzido em aproximadamente $41 \%$. Em linhas gerais, pode-se concluir que o incremento no preço social (preço que deveria existir - ou preço-meta numa política de desoneração da cadeia, em caso de adoção de políticas de redução do Custo-País incidentes nas atividades econômicas) aumentou a desproteção sobre as cadeias produtivas do leite em pó integral em análise.

Esses achados não estão em linha com o resultado observado por Guba (2000), que analisou a cadeia produtiva do leite em pó desnatado na Polônia, pois o valor do CL foi positivo e superior à unidade (1), o que apontou para uma proteção sobre a cadeia produtiva, beneficiando os agentes envolvidos na cadeia. Porém, como se trata de objetos de estudos distintos, principalmente pelo fator temporal das pesquisas e de perfil das cadeias produtivas, torna-se difícil tecer análises comparativas. No entanto, é importante e relevante o registro no intuito de ampliar o conhecimento, bem como de difundir a aplicação da PAM como ferramenta para a análise da competitividade de cadeias produtivas agrícolas. De uma perspectiva nacional, a partir dos resultados da aplicação da PAM por Martins (2002), pode-se constatar que a situação continua sendo de penalização (políticas públicas e falhas de mercado) sobre a cadeia produtiva do leite em pó no Rio Grande do Sul, conforme os resultados aqui levantados. Assim, traçando-se um paralelo entre os resultados observados na presente pesquisa, verificou-se uma semelhança entre os valores, pois a CPLEI-II, que foi a mais penalizada, apresentou um CL $=0,42$, o que sinaliza a continuidade da penalização.

Em termos gerais, apesar da situação de penalização sobre as cadeias produtivas pela presença de políticas equivocadas, distorções significativas de preços, medidas protecionistas ineficientes (subsídios à produção e/ou à comercialização) e desequilíbrios no Sistema Tributário do Brasil (STB), que afetam o lucro privado das cadeias produtivas do leite em pó integral, as cadeias produtivas ainda se mostram viáveis economicamente; porém, a situação poderia ser mais estimulante caso o nível de competitividade não fosse comprometido pelos atuais valores dos CLs, pois limitam os LPs. Vale mencionar que o valor do indicador CL é importante para dimensionar a diferença em termos numéricos (valor em $\mathrm{R} \$$ ) entre o LP e o LS.

Assim, quanto maior a diferença entre os $\mathrm{LP}_{\mathrm{S}}$ e $\mathrm{LS}_{\mathrm{S}}$, maiores são as interferências que oneram o lucro dos produtores de leite em pó integral e maior a urgência de políticas de elevação da competitividade. No caso desses três níveis tecnológicos, essas diferenças devem-se basicamente à menor diferença entre os custos dos fatores domésticos no nível tecnológico alto. Por esse indicador, o nível tecnológico mais lucrativo é o da CPLEI-III, que usa alta genética, pastagem natural e todas as demais recomendações sanitárias, além de vender diariamente um grande volume de produção de alta qualidade, o que lhe confere um preço mais elevado pago pela cooperativa, uma vez que o leite é pago ao produtor rural em função do volume e qualidade.

\section{Análise de eficiência}

A Tabela 6 apresenta os resultados da PAM referentes aos indicadores de eficiência, protecionismo e transferência de políticas sobre as cadeias produtivas do leite em pó integral no Rio Grande do Sul, Brasil. 
Tabela 6

Eficiência, Protecionismo e Transferência de Políticas sobre as Cadeias Produtivas do Leite em Pó Integral no Rio Grande do Sul, Brasil

\begin{tabular}{lccc}
\hline \multicolumn{1}{c}{ Indicadores privados e sociais } & CPLEI-I & CPLEI-II & CPLEI-III \\
\hline $\mathbf{R C P}=$ C/(A-B) & 0,46 & 0,72 & 0,26 \\
$\mathbf{R C D}=$ G/(E-F) & 0,26 & 0,47 & 0,14 \\
$\mathbf{C P N}=$ A/E & 0,95 & 0,95 & 0,95 \\
$\mathbf{C P E}=(\mathrm{A}-\mathrm{B}) /(\mathrm{E}-\mathrm{F})$ & 0,75 & 0,79 & 0,69 \\
$\mathbf{R S P}=\mathrm{L} / \mathrm{E}$ & $(0,08)$ & $(0,08)$ & $(0,06)$ \\
$\mathbf{T L P}=$ D-H & $(\mathrm{R} \$:$ : 888,98$)$ & $(\mathrm{R} \$: 732,76)$ & $(\mathrm{R} \$: 594,22)$ \\
\hline
\end{tabular}

Nota. Fonte: Elaborado pelos autores.

No que tange à Razão do Custo Privado (RCP), de acordo com a Tabela 6, todas as cadeias de diferentes níveis tecnológicos são competitivas, conforme os índices auferidos pelas RCPs, pois os resultados apresentados foram menores que 1, como segue: CPLEI-III: 0,26; CPLEI-I: 0,46; e CPLEIII: 0,72 . Portanto, verifica-se que todas as cadeias produtivas do leite em pó integral estudadas são rentáveis para os agentes envolvidos, pois estes recebem remuneração positiva e líquida acima dos custos de oportunidade, depreciação, tributação e falhas de mercado.

Os resultados das RCPs permitiram compreender que, na CPLEI-III $(0,26)$, os fatores domésticos (terra, capital e trabalho) foram mais bem explorados pela atividade leiteira. Isto, por sua vez, apresentou um retorno acima do normal em relação às demais cadeias, logo, é possível concluir que a CPLEI-III apresenta as condições mais competitivas entre as cadeias produtivas estudadas, uma vez que, em comparando-se os valores dos fatores domésticos, estes foram proporcionalmente menores. Consequentemente, a CPLEI-III apresentou a maior lucratividade entre as cadeias, com o valor de $\mathrm{R} \$ 857,86$ por tonelada de leite em pó integral, seguida da CPLEI-I, que apresentou uma lucratividade de $\mathrm{R} \$ 850,13$ por tonelada de leite em pó integral.

Na Razão dos Custos dos Recursos Domésticos (RCD), os valores correspondentes foram todos positivos e menores que a unidade (1), a saber: CPLEI-III: 0,14; CPLEI-I: 0,26; e CPLEI-II: 0,47. Logo, esses resultados indicam eficiência econômica e a existência de vantagem competitiva nas cadeias produtivas em relação ao preço internacional do leite em pó integral.

Portanto, ocorreu um ganho líquido, pois os recursos domésticos empregados foram nominalmente inferiores ao valor adicionado (medido pelo resultado da diferença entre a receita e os custos dos insumos comercializáveis). Assim, compreende-se que o valor adicionado foi mais do que suficiente para remunerar os fatores de produção, considerando o custo de oportunidade e a depreciação. Com isso, tem-se que, para cada $\mathrm{R} \$ 1,00$ economizado com a importação, seriam utilizados os seguintes valores de recursos domésticos: na CPLEI-III, R \$ 0,14; na CPLEI-I, R \$ 0,26; e, na CPLEI-II, R \$ 0,47. Ressalta-se, ainda, que a CPLEI-III apresentou a maior eficiência econômica na alocação de recursos entre as cadeias produtivas estudadas, gastando apenas $\mathrm{R} \$ 0,14$ para cada $\mathrm{R} \$ 1,00$ aplicado para substituir a importação ou gerar divisas ao país na exportação do respectivo produto em análise.

\section{Análise de proteção}

Para o Coeficiente de Proteção Nominal (CPN), os valores correspondentes foram todos positivos e menores que a unidade (1), como: CPLEI-I: 0,95; CPLEI-II: 0,95; e CPLEI-III: 0,95. Desse modo, os indicadores encontrados demonstraram que as cadeias produtivas estavam desprotegidas, ou seja, ocorreu uma falta de proteção aos preços domésticos, o que resultou em menor valor recebido pelos agentes da cadeia produtiva do leite em pó integral, mesmo que a atividade tenha apresentado lucratividade. 
Os índices demonstraram que as cadeias produtivas receberam valores menores do que aqueles que deveriam ser recebidos, o que, de maneira implícita, reduziu o preço recebido pelo leite em pó integral. Os resultados indicam uma redução de 5\% sobre o valor recebido pelo respectivo produto, ao considerar-se que os preços internos apresentaram distorções.

Verificou-se que os resultados obtidos por Martins (2002), que adotou critério semelhante com a PAM para o cálculo do CPN, coincidem com o deste estudo. Foi possível constatar que todas as cadeias produtivas de leite em pó estavam desprotegidas, com o valor do indicador do CPN tendo sido de 0,63, indicando uma penalização de $37 \%$ sobre o valor pago pelo produto, ou seja, a cadeia produtiva teve uma redução de $37 \%$ no valor recebido pelo leite em pó, o que de forma direta afetou o LP. Portanto, ao se comparar os respectivos resultados com as cadeias em análise, percebe-se que ocorreu redução na desproteção sobre o preço do produto.

Considerando-se o Coeficiente de Proteção Efetiva (CPE), os valores correspondentes foram positivos e inferiores à unidade (1), com os seguintes valores: CPLEI-II: 0,79; CPLEI-I: 0,75; e CPLEIIII: 0,69. Em face dos resultados dos $\mathrm{CPE}_{\mathrm{S}}$, foi possível perceber que as cadeias produtivas apresentaram valores adicionais, a preços privados, conforme segue: CPLEI-II: 21\%; CPLEI-I: 25\%; e CPLEI-III: $31 \%$. Isso significa que houve uma desproteção ou taxação (em percentual) sobre o produto leite em pó integral, bem como sobre os insumos comercializados que compõem as cadeias produtivas; tal constatação é assegurada pela natureza do respectivo indicador, isto é, as cadeias produtivas foram penalizadas no que diz respeito às políticas de preços de produtos e de insumos comercializados, crescendo com o aumento do nível tecnológico adotado.

Nota-se que a situação atual é menos grave, pois, de acordo com Martins (2002, pp. 154-155), "os valores de CPE oscilaram de 0,43 a 0,50", e, depois de uma década, a presente pesquisa indica que o CPE apresentou valores que oscilaram de 0,69 a 0,79. Essa constatação indica que 10 anos depois ocorreu menor transferência de renda dos agentes dessa cadeia produtiva para a sociedade, por meio de impostos ou minimização de falhas de mercado. Acredita-se que esse cenário resultou da intervenção política que afetou diretamente os preços dos insumos, que por sua vez foram alocados aos produtos, comprometendo a competitividade dessas cadeias produtivas em análise. No entanto, a situação ainda requer atenção, pois há uma penalização forte sobre as cadeias produtivas.

\section{Análise de transferência de políticas}

No que concerne à Transferência Líquida de Políticas (TLP), verificou-se que todos os resultados dos TLPS foram negativos, com os seguintes valores: CPLEI-II: R \$ -732,76; CPLEI-I: R \$ 688,98; e CPLEI-III: R \$ -594,22, por tonelada de leite em pó integral. Esses valores são resultado da diferença entre os valores correntes (valores privados) e os valores que deveriam existir se não ocorressem as tributações e outras distorções de mercado. No entanto, mesmo que esses valores apontem para um desequilíbrio na lucratividade, isso não determina a inviabilidade econômica das cadeias produtivas, principalmente porque os resultados dos LPs apontaram para o lucro.

Partindo-se desse pressuposto, pode-se inferir que houve divergências entre os preços domésticos, o que pode ser reflexo de políticas públicas ineficientes (tributária, fiscal, cambial, monetária, de investimentos, tecnológica, ambiental, de comércio exterior, alfandegária, de serviços, de transportes, de comunicações, agrícola, industrial, trabalhista, entre outras).

Na Razão de Subsídio ao Produtor (RSP), todos os valores foram negativos. Isto significa que as cadeias foram taxadas e com valores próximos ao índice numérico de zero (0), com os seguintes valores: CPLEI-III: -0,06; CPLEI-I: -0,08; e CPLEI-II: -0,08. As cadeias produtivas analisadas sofrem desproteção ou algumas taxações, com 6\% na cadeia mais tecnificada (CPLEI -III) e 8\% nas outras, confirmando aquilo que ficou evidenciado nos demais indicadores: o uso de mais insumos (aqui tomados como referência de emprego de tecnologias modernas e, portanto, de inovação na produção de leite nas propriedades rurais) está sendo penalizado pelas políticas distorcivas da competitividade do Brasil. 
Por essa especificidade, torna-se relevante lembrar que as cadeias produtivas analisadas são relativamente longas, por isso os agentes, em geral, têm um alto percentual de incremento de impostos que oneram gradativamente e taxam duplamente os agentes privados dos quatros elos dessas cadeias. Os resultados das RSPs vêm ratificar esse entendimento, isto é, evidenciar a presença de penalização sobre a cadeia na forma de desproteção.

Assim, constata-se que há eficiência econômica (ou vantagem comparativa) nas cadeias produtivas do leite em pó integral analisadas. Logo, em termos de competitividade, mais precisamente à luz da vantagem comparativa, os indicadores revelam a viabilidade ou a manutenção da atividade econômica (Siqueira \& Pinha, 2012). Nesse sentido, os resultados indicam que estão em consonância com o pensamento de Krugman, Obstfeld e Diniz (2007).

Desse modo, os achados fortalecem a tese de que a lucratividade privada foi reduzida em função dos elevados custos de produção, que por sua vez sofrem impactos pela incidência de tributos. De uma perspectiva teórica (competitividade - vantagem comparativa), esse fato pode ser entendido como um processo de intercâmbio em que os agentes das cadeias podem ser beneficiados nas relações mercadológicas; assim, uma cadeia produtiva pode apresentar um desempenho intermediário, sem que necessariamente ocorra a necessidade de ter condições absolutas e plenas de concorrer (Krugman, Obstfeld, \& Diniz, 2007).

\section{Simulação da variável preço pago (redução de 10\%) ao leite em pó integral}

De acordo como a Tabela 7, as três cadeias produtivas analisadas tiveram as lucratividades afetadas em relação aos valores dos $\mathrm{LP}_{\mathrm{S}}$ e não apresentaram competitividade, e sim prejuízos com essa redução no valor pago ao leite em pó integral. Observou-se que os LP $\mathrm{S}_{\mathrm{S}}$ foram todos negativos, ou seja, na forma de prejuízo, com os valores respectivos: CPLEI-III: R \$ -15,14; CPLEI-I: R \$ -22,87; e CPLEIII: $\mathrm{R} \$-335,46$, por tonelada.

Tabela 7

Lucratividade e Divergências de Preços nas Cadeias Produtivas de Leite em Pó Integral no Rio Grande do Sul - Brasil, Calculadas pelo Método da PAM em R\$/Tonelada (Mediante a Redução de $10 \%$ sobre o Valor Pago ao Leite em Pó Integral)

\begin{tabular}{|c|c|c|c|c|c|c|c|c|}
\hline \multirow{3}{*}{$\begin{array}{c}\text { CADEIA } \\
\text { PRODUTIVA } \\
\text { CPLEI-I }\end{array}$} & \multirow{2}{*}{\multicolumn{2}{|c|}{ RECEITA }} & \multicolumn{4}{|c|}{ CUSTOS DE PRODUÇÃO } & \multirow{2}{*}{\multicolumn{2}{|c|}{ LUCROS }} \\
\hline & & & \multicolumn{2}{|c|}{$\begin{array}{c}\text { Insumos } \\
\text { comercializáveis }\end{array}$} & \multicolumn{2}{|c|}{ Fatores domésticos } & & \\
\hline & Base & CI & Base & CI & Base & CI & Base & CI \\
\hline \multirow[t]{2}{*}{ Preços privados } & \multicolumn{2}{|c|}{ A } & \multicolumn{2}{|c|}{ B } & \multicolumn{2}{|c|}{$\mathrm{C}$} & \multicolumn{2}{|c|}{ D } \\
\hline & $8.730,00$ & $7.857,00$ & $7.167,21$ & $7.167,21$ & 712,66 & 712,66 & 850,13 & $-22,87$ \\
\hline \multirow[t]{2}{*}{ Preços sociais } & \multicolumn{2}{|c|}{$\mathrm{E}$} & \multicolumn{2}{|c|}{$\mathrm{F}$} & \multicolumn{2}{|c|}{ G } & \multicolumn{2}{|c|}{$\mathrm{H}$} \\
\hline & $9.166,5$ & $8.249,85$ & $7.087,41$ & $7.087,41$ & 539,98 & 539,98 & $1.539,11$ & 622,46 \\
\hline \multirow{2}{*}{$\begin{array}{l}\text { Efeito de } \\
\text { divergências }\end{array}$} & \multicolumn{2}{|c|}{ I } & \multicolumn{2}{|c|}{$\mathrm{J}$} & \multicolumn{2}{|c|}{ K } & \multicolumn{2}{|c|}{$\mathrm{L}$} \\
\hline & $-436,5$ & $-392,85$ & 79,8 & 79,8 & 172,68 & 172,68 & $-688,98$ & $-645,33$ \\
\hline CPLEI-II & Base & $\mathrm{CI}$ & Base & $\mathrm{CI}$ & Base & CI & Base & $\mathrm{CI}$ \\
\hline \multirow[t]{2}{*}{ Preços privados } & \multicolumn{2}{|c|}{ A } & \multicolumn{2}{|c|}{ B } & \multicolumn{2}{|c|}{$\mathrm{C}$} & \multicolumn{2}{|c|}{$\mathrm{D}$} \\
\hline & $8.730,00$ & $7.857,00$ & $6.833,22$ & $6.833,22$ & $1.360,24$ & $1.360,24$ & 536,54 & $-336,46$ \\
\hline
\end{tabular}


Tabela 7 (continuação)

\begin{tabular}{|c|c|c|c|c|c|c|c|}
\hline \multirow{2}{*}{$\begin{array}{c}\text { CADEIA } \\
\text { PRODUTIVA }\end{array}$} & \multirow{2}{*}{\multicolumn{2}{|c|}{ RECEITA }} & \multicolumn{4}{|c|}{ CUSTOS DE PRODUÇÃO } & \multirow[t]{2}{*}{ LUCROS } \\
\hline & & & \multicolumn{2}{|c|}{$\begin{array}{l}\text { Insumos } \\
\text { comercializáveis }\end{array}$} & \multicolumn{2}{|c|}{ Fatores domésticos } & \\
\hline \multirow[t]{2}{*}{ Preços sociais } & \multicolumn{2}{|c|}{$\mathrm{E}$} & \multicolumn{2}{|c|}{$\mathrm{F}$} & \multicolumn{2}{|c|}{$\mathrm{G}$} & $\mathrm{H}$ \\
\hline & $9.166,5$ & $8.249,85$ & $6.753,84$ & $6.753,84$ & $1.142,36$ & $1.142,36$ & $1.270,30 \quad 353,65$ \\
\hline \multirow{2}{*}{$\begin{array}{l}\text { Efeito de } \\
\text { divergências }\end{array}$} & \multicolumn{2}{|c|}{ I } & \multicolumn{2}{|c|}{$\mathrm{J}$} & \multicolumn{2}{|c|}{ K } & $\mathrm{L}$ \\
\hline & $-436,50$ & $-392,85$ & 79,38 & 79,38 & 217,88 & 217,88 & $\begin{array}{ll}-733,76 & -690,11\end{array}$ \\
\hline CPLEI-III & Base & $\mathrm{CI}$ & Base & CI & Base & $\mathrm{CI}$ & Base \\
\hline \multirow[t]{2}{*}{ Preços privados } & \multicolumn{2}{|c|}{ A } & \multicolumn{2}{|c|}{ B } & \multicolumn{2}{|c|}{$\mathrm{C}$} & $\mathrm{D}$ \\
\hline & $8.730,00$ & $7.857,00$ & $7.570,81$ & $7.570,81$ & 301,33 & 301,33 & $857,86 \quad-15,14$ \\
\hline \multirow[t]{2}{*}{ Preços sociais } & \multicolumn{2}{|c|}{$\mathrm{E}$} & \multicolumn{2}{|c|}{$F$} & \multicolumn{2}{|c|}{ G } & $\mathrm{H}$ \\
\hline & $9.166,50$ & $8.249,85$ & $7.484,45$ & $7.484,45$ & 229,97 & 229,97 & $1.452,08 \quad 535,43$ \\
\hline \multirow{2}{*}{$\begin{array}{l}\text { Efeito de } \\
\text { divergências }\end{array}$} & \multicolumn{2}{|c|}{$\mathrm{I}$} & \multicolumn{2}{|c|}{$\mathrm{J}$} & \multicolumn{2}{|c|}{$\mathrm{K}$} & $\mathrm{L}$ \\
\hline & $-436,50$ & $-392,85$ & 86,36 & 86,36 & 71,36 & 71,36 & $-594,22 \quad-550,57$ \\
\hline
\end{tabular}

Nota. Fonte: Elaborado pelos autores.

Ao se considerar os ganhos na atividade econômica (a valores privados), a redução do valor pago pelo leite em pó integral (no estudo, cotado em $\mathrm{R} \$ 7.857,00$ por tonelada) foi decisiva para a competitividade das cadeias produtivas. Portanto, o fator preço tem forte interferência na rentabilidade econômica dessa atividade. Este fato requer uma atenção especial, pois se trata de uma commodity e esta sofre impactos no comércio internacional, com acentuada volatilidade de preços, variações significativas nos custos de produção ou alterações nas taxas de câmbio e de juros. Todos são fatores que podem agravar a capacidade de competir nos mercados, bem como inviabilizar essas cadeias produtivas.

No que se refere aos demais indicadores da PAM, verificou-se que essa redução no preço do leite em pó integral também impactou de forma negativa nos indicadores, tanto nos relacionados à competitividade (a valores privados) quanto nos relativos à eficiência econômica (a valores sociais), como pode ser visto na Tabela 8 .

Tabela 8

Simulação da Variável Preço (Mediante a Redução de 10\% sobre o Valor Pago ao Leite em Pó Integral) e seus Efeitos nos Indicadores da PAM para as Cadeias Produtivas de Leite em Pó Integral no Rio Grande do Sul - Brasil

\begin{tabular}{lcccccc}
\hline & \multicolumn{2}{c}{ CPLEI-I } & \multicolumn{2}{c}{ CPLEI-II } & \multicolumn{2}{c}{ CPLEI-III } \\
\cline { 2 - 7 } Indicadores privados e sociais & Base & CI & Base & CI & Base & CI \\
\hline $\mathbf{R C P}=$ C/(A-B) & 0,46 & 1,03 & 0,72 & 1,33 & 0,26 & 1,05 \\
$\mathbf{R C D}=$ G/(E-F) & 0,26 & 0,46 & 0,47 & 0,76 & 0,14 & 0,30 \\
$\mathbf{C P N}=$ A/E & 0,95 & 0,95 & 0,95 & 0,95 & 0,95 & 0,95 \\
$\mathbf{C P E}=(\mathrm{A}-\mathrm{B}) /(\mathrm{E}-\mathrm{F})$ & 0,75 & 0,59 & 0,79 & 0,69 & 0,69 & 0,37 \\
$\mathbf{C L}=$ D/H & 0,55 & $-0,04$ & 0,42 & $-0,95$ & 0,59 & $-0,03$ \\
$\mathbf{R S P}=$ L/E & $(0,08)$ & $(0,08)$ & $(0,08)$ & $(0,08)$ & $(0,06)$ & $(0,07)$ \\
\hline
\end{tabular}

Nota. Fonte: Elaborado pelos autores. 
Conforme a Tabela 8 , os resultados das $\mathrm{RCP}_{\mathrm{S}}$ inferem que as cadeias produtivas não apresentaram competitividade, logo, não conseguiram remunerar todos os custos com os insumos comercializáveis e os fatores domésticos (terra, capital e trabalho), como se fazia necessário para a atividade ser rentável. Os resultados diferentes para esse indicador não sinalizam uma maior taxa de retorno positiva entre as cadeias produtivas; ao contrário, apontam para um contexto de penalização nas cadeias produtivas.

Para todas as cadeias produtivas, os indicadores de $\mathrm{RCP}_{\mathrm{S}}$ apresentaram um valor superior à unidade (1). Isso significa dizer que o valor adicionado foi inferior ao valor necessário para pagar os custos de produção referentes aos fatores domésticos, conforme segue: CPLEI-I com RCP = 1,03 (a menos penalizada); CPLEI-III com RCP = 1,05; e CPLEI-II com RCP = 1,33 (a mais penalizada). Logo, esse resultado aponta para uma ineficiência econômica das cadeias produtivas, o que indica prejuízo. $\mathrm{O}$ mais adequado seria que as $\mathrm{RCP}_{\mathrm{S}}$ fossem menores que a unidade (1), pois isso significaria que todos os fatores domésticos haviam sido remunerados adequadamente, sem que ocorresse prejuízo para os agentes econômicos envolvidos.

Por fim, verificou-se que os demais indicadores presentes na Tabela 8 seguem a mesma tendência que os outros indicadores já apresentados, ou seja, indicando que não há competitividade (a valores privados) e não há eficiência econômica (a valores sociais). Portanto, considerando a situação de redução de $10 \%$ no valor pago ao leite em pó integral, as cadeias produtivas em análise tendem a gerar as seguintes situações: descapitalização dos agentes envolvidos, o capital investido não receberá a remuneração adequada e os custos de oportunidade e a depreciação serão desconsiderados nos custos totais de produção das cadeias produtivas. Desse modo, isso provoca prejuízos para os agentes das cadeias produtivas, o que pode afetar a viabilidade ou a manutenção dessa atividade econômica.

\section{Conclusões}

O objetivo principal deste trabalho foi analisar a competitividade de três cadeias produtivas do leite em pó integral no Rio Grande do Sul, Brasil, com três diferentes níveis tecnológicos (baixo, médio e alto) no elo de produção de matéria-prima, por meio do método da Policy Analysis Matrix (PAM).

De maneira geral, conclui-se que todos os níveis tecnológicos (baixo, médio e alto) estudados nas respectivas cadeias produtivas analisadas, independentemente do nível de inovação adotado nos estabelecimentos representativos (previamente e criteriosamente selecionados), foram competitivos e apresentaram eficiência econômica. A PAM permitiu verificar que existem diferenças entre as penalizações das cadeias produtivas estudadas segundo o nível tecnológico adotado pelos pecuaristas, as quais foram confirmadas pelas análises do Coeficiente de Proteção Efetiva (CPE), Transferência Líquida de Políticas (TLP) e Razão de Subsídio ao Produtor (RSP), o que produziu efeito sobre o Coeficiente de Lucratividade (CL).

Os resultados de competitividade e eficiência evidenciam uma ligação com os níveis tecnológicos adotados pelos agricultores e os índices de desempenho econômico das cadeias produtivas de leite em pó integral. Nesse sentido, a CPLEI-III, com nível tecnológico alto e grande volume de leite produzido (Tabela 4), mostra-se como uma cadeia produtiva de desempenho competitivo e com eficiência na locação de recursos produtivos. Também apresenta a menor divergência entre os custos privados e os custos sociais dos fatores domésticos, denotando pouco uso de recursos como terra, capital e trabalho para gerar receitas líquidas. Essa condição de alta genética, sanidade, alimentação a pasto e grande volume de entrega diária também contribuiu para que o nível tecnológico alto apresentasse a maior lucratividade entre as três estudadas.

No que concerne à redução de $10 \%$ no preço pago ao leite em pó integral, simulada no estudo, percebe-se que, nessa condição (ou cenário), não há competitividade e não há eficiência econômica nesse segmento em nenhum dos níveis tecnológicos das cadeias produtivas analisadas. 
Uma importante implicação deste estudo para o agronegócio do leite em pó é que, do ponto de vista dos futuros investimentos em níveis tecnológicos no elo de produção de matéria-prima, fazem-se necessárias políticas públicas setoriais para elevar a competitividade do setor. Essa inferência é fruto dos conjuntos de resultados dos indicadores da CPLEI-II (para nível tecnológico médio). Verificou-se que, para a pecuária, existe uma relação que é inversa entre usar mais fatores domésticos (terra, capital e trabalho) e o aumento da lucratividade. Assim, outras análises necessitam ser feitas para aprimorar os efeitos penalizadores de políticas tributárias sobre os índices de inovação, os quais impactam sobre os custos de produção e possivelmente são afetados pela taxação indireta e pouco visível aos agentes da cadeia sobre os insumos em geral. Especificamente, considerando o tamanho da propriedade produtora de leite in natura, os resultados indicam uma maior viabilidade econômica para as grandes propriedades, em virtude da atual política de pagamento do litro de leite ao produtor rural, que paga mais por grandes volumes diários, ocorrendo o contrário para pequenas quantidades geradas na agricultura familiar.

Os achados desta pesquisa fornecem um conjunto de indicadores econômicos que podem ser de grande importância na tomada de decisão e no apoio à formulação de novas políticas de preços ou tributárias, bem como na perspectiva de se construir um instrumento de avaliação capaz de contribuir estrategicamente com o agronegócio do leite em pó integral brasileiro num horizonte de longo prazo. Recomenda-se, em novos estudos, o uso de dados e informações de países do Mercosul, em função da similaridade geográfica e, em especial, pelo fato de esses países já terem realizado as reformas físcais, tributárias e trabalhistas.

Por fim, devem-se destacar as seguintes limitações encontradas no decorrer deste estudo: a delimitação territorial restrita ao Rio Grande do Sul e a reduzida representatividade tornaram o estudo de caráter regional; a amplitude da caracterização ou categorização dos estabelecimentos representativos dos produtores de leite in natura; as alternativas de conversão de preços privados para preços sociais via decomposição de preços de exportação Free on Board (FOB), ou livre dos encargos de exportação, para os produtos a serem comercializados no mercado internacional; a disponibilidade de dados e estudos que agrupem os principais elos da cadeia produtiva do leite em pó integral.

\section{Agradecimentos}

Ao Conselho Nacional de Desenvolvimento Científico e Tecnológico (CNPq), pela bolsa de doutorado concedida, bem como à Empresa Brasileira de Pesquisa Agropecuária (Embrapa Clima Temperado, em especial), pela contribuição de seus pesquisadores, e à cooperativa parceira nesse estudo.

\section{Referências}

Barrera-Rodriguez, A. I., Jaramillo-Villanueva, J. L., Escobedo-Garrido, J. S., \& Herrera-Cabrera, B. E. (2011). Profitability and competitiveness of the vanilla (Vanilla planifolia J.) production systems in the totonacapan región. Agrociencia, 45(5), 625-638.

Bernal, L. E. P., Lara-Herrera, A., Reyes-Rivas, E., \& Perez-Veyna, O. (2012, June). Competitiveness, efficiency and environmental impact of protected agriculture in zacatecas, Mexico. Proceedings of the International Food and Agribusiness Management Review, Shanghai, China, 22.

Bobadilla-Soto, E. E., Espinoza-Ortega, A., \& Martínez-Castañeda, F. E. (2013). Swine piglet breeding farms competitiveness and profitability. Revista Mexicana de Ciencias Pecuarias, 4(1), 87-92.

Calegar, G. M. (2001). Competitividade dos produtos lácteos do Estado de Goiás. In R. C. M. T. Vieira, A. R. Teixeira Filho, A. J. Oliveira, \& M. R. Lopes (Eds.), Cadeias produtivas no Brasil: análise da competitividade (pp. 205-238). Brasília, DF: Embrapa. 
Carneiro, A. V., \& Siqueira, K. B. (2013, fevereiro). Conjuntura do mercado - lácteo. Boletim Eletrônico Mensal, Ano 6 (46), 1-16. Recuperado de http://www.infoteca.cnptia.embrapa.br/infoteca/bitstream/doc/960144/1/201302Comercio20Inte rnacionalLeite.pdf

Centro de Estudos Avançados em Economia Aplicada - Escola Superior de Agricultura Luiz de Queiroz/Universidade de São Paulo - Confederação da Agricultura e Pecuária do Brasil. (2013). Preços ao produtor: Cepea - valores nominais do leite (R\$/Litro). Piracicaba, SP: Universidade de São Paulo - USP. Recuperado de http://www.cepea.esalq.usp.br/leite/?page=155

Centro de Orientação Fiscal. (2012). Manual de procedimentos: ICMS, IPI, ISS - Outros e legislação $R S$ [Manual]. Rio Grande do Sul, RS: CENOFISCO. Recuperado de http://boletim.lex.com.br/arquivos/virtualpaper/vt_rs_20-12.pdf

Currid-Halkett, E., \& Stolarick, K. (2011). The great divide: economic development theory versus practice-a survey of the current landscape. Economic Development Quarterly, 25(2), 143-157. doi: $10.1177 / 0891242410394358$

Food and Agriculture Organization of the United Nations. (n.d.). Production: livestock primary - camel milk, whole, fresh. Roma: Author. Retrieved from http://faostat.fao.org/site/569/DesktopDefault.aspx?PageID=569\#ancor

Guba, W. (2000). Competitiveness of polish milk processing industry during the integration to the European Union - Analysis of dynamic comparative advantages (Doctoral thesis). Faculty of Agricultural Sciences Georg-August-University Göttingen, Göttingen, Alemanha.

Haguenauer, L. (2012). Competitividade: conceitos e medidas: uma resenha da bibliografia recente com ênfase no caso brasileiro. Revista de Economia Contemporânea, 16(1), 146-176. doi: 10.1590/s1415-98482012000100008

Instituto Brasileiro de Geografia e Estatística. (n.d.b). Tabela 73 - Efetivo dos rebanhos por tipo de rebanho. Brasília, DF: Autor. Recuperado de http://www.sidra.ibge.gov.br/bda/tabela/listabl.asp?c=73\&z=p\&o=27

Instituto Brasileiro de Geografia e Estatística. (n.d.a). Tabela 74 - Produção de origem animal por tipo de produto. Brasília, DF: Autor. Recuperado de http://www.sidra.ibge.gov.br/bda/tabela/listabl.asp?c=74\&z=t\&o=24

Instituto Brasileiro de Geografia e Estatística. (n.d.c). Tabela 94 - Vacas ordenhadas. Brasília, DF: Autor. Recuperado de http://www.sidra.ibge.gov.br/bda/tabela/listabl.asp?c=94\&z=p\&o=27

Katic, P. G., Namara, R. E., Hope, L., Owusu, E., \& Fujii, H. (2013). Rice and irrigation in West Africa: achieving food security with agricultural water management strategies. Water Resources and Economics, 1, 75-92. doi: 10.1016/j.wre.2013.03.001

Krugman, P. R., Obstfeld, M., \& Diniz, E. M. (2007). Economia internacional: teoria e política (6a ed.). São Paulo, SP: Pearson Education do Brasil.

Lopes, M. R., Belarmino, L. C., Oliveira, A. J. de, Torres, D. A. P., Talamini, D. J. D., Martins, F. M., \& Lima, J. R., Filho (2012). Matriz de análise de política: metodologia e análise. Brasília, DF: Embrapa.

Maithya, J. M., Kimenye, L. N., Mugivane, F. I., \& Ramisch, J. J. (2006). Profitability of agro-forestry based soil fertility management technologies: the case of small holder food production in Western Kenya. Nutrient Cycling in Agroecosystems, 76(2/3), 355-367. doi: 10.1007/s10705-006-9062-6 
Mane-Kapaj, A., Kapaj, I., Chan-Halbrendt, C., \& Totojani, O. (2010, June). Assessing the comparative advantage of Albanian olive oil production. Proceedings of the International Food and Agribusiness Management Review, Boston, USA, 20.

Martin, F. S., \& Noordwijk, M. van (2011). Is native timber tree intercropping an economically feasible alternative for smallholder farmers in the Philippines? Australian Journal of Agricultural and Resource Economics, 55(2), 257-272. doi: 10.1111/j.1467-8489.2011.00530.x

Martins, P. C. (2002). Políticas públicas e mercados deprimem o resultado do sistema agroindustrial do leite (Tese de doutorado). Escola Superior de Agricultura Luiz de Queiroz, Universidade de São Paulo, São Paulo, SP, Brasil.

Monke, E. A., \& Pearson, S. R. (1989). The policy analysis matrix for agricultural development. New York: Cornell University Press.

Nelson, G. C., \& Panggabean, M. (1991). The costs of Indonesian sugar policy - A policy analysis matrix approach. American Journal of Agricultural Economics, 73(3), 703-712. doi: 10.2307/1242822

Picazo-Tadeo, A. J., \& Wall, A. (2011). Production risk, risk aversion and the determination of risk attitudes among Spanish rice producers. Agricultural Economics, 42(4), 451-464. doi: 10.1111/j.1574-0862.2011.00537.x

Rastegaripour, F., Tavassoli, A., Rastegaripour, N. K., Piri, I., \& Karbasi, A. (2011). Comparative advantage analysis of bottled drinking water factory: a case study of Khorasan Region, Iran. African Journal of Business Management, 5(30), 11978-11983. doi: 10.5897/ajbm11.597

Sabaouhi, M., Ghanbari, A., Rastegaripour, F., Tavassoli, A., \& Esmaeilian, Y. (2011). Economic evaluation and applications of the Policy Analysis Matrix of sole and intercropping of leguminous and cereals case study: Shirvan city-Iran. African Journal of Biotechnology, 10(78), 1794817953. doi: 10.5897/ajb11.403

Siqueira, K. B., \& Pinha, L. C. (2012). Vantagens comparativas reveladas e o contexto do Brasil no comércio internacional de lácteos. Informações Econômicas, 42(3), 40-49. Recuperado de $\mathrm{ftp} / / / \mathrm{ftp}$. sp.gov.br/ftpiea/publicacoes/ie/2012/tec5-0612.pdf

Sirajuddin, S. N., Siregar, H., Amrawaty, A. A., Jusoff, K., Nurlaelah, S., Rohani, S., \& Hastang. (2013). Comparative advantage analysis on self dependent and business partnership of dairy farmers. Global Veterinaria, 10(2), 165-170. doi: 10.5829/idosi.gv.2013.10.2.7240

Soares, N. S., Silva, M. L. da, Rezende, J. L. P. de, Jacovine, L. A. G., \& Valverde, S. R. (2013). Competitiveness of wood pulp production in different Brazilian states. Cerne, 19(2), 297-305. doi: 10.1590/S0104-77602013000200014

Sousa, E. P. de, Soares, N. S., Cordeiro, S. A., \& Silva, M. L. da (2011). Competitividade da produção de palmito de pupunha no Espírito Santo e em São Paulo. Revista de Economia e Sociologia Rural, 49(1), 157-179. doi: 10.1590/s0103-20032011000100007

United States Department of Agriculture. (2012). Dairy: world markets and trade. United States: Author. Retrieved from http://usda.mannlib.cornell.edu/usda/fas/dairymarket//2010s/2012/dairy-market-12-14-2012.pdf

Vieira, R. C. M. T., Teixeira, A. R., Filho, Oliveira, A. J. de, \& Lopes, M. R. (2001). Cadeias produtivas no Brasil - Análise da competitividade. Revista de Políticas Agrícola, 10(2), 7-15.

Zheng, S., Lambert, D., Wang, S., \& Wang, Z. (2013). Effects of agricultural subsidy policies on comparative advantage and production protection in China. Chinese Economy, 46(1), 20-37. doi: 10.2753/CES1097-1475460102 


\section{Dados dos Autores}

João Batista de Freitas

BR 405, Km 03, Arizona, 59900-000, Pau dos Ferros, RN, Brasil. E-mail: freitasjb.brasil@ gmail.com

Jean Philippe Palma Revillion

Av. Bento Gonçalves 7712, 91540-000, Porto Alegre, RS, Brasil. E-mail: jeanppr@ gmail.com

Luiz Clovis Belarmino

BR 392 Km 78, Distrito de Cascata, 96001-970, Pelotas, RS, Brasil. E-mail: luiz.belarmino@embrapa.br 